\section{Lady Health Workers: Impact on Knowledge of Modern Contraceptive Methods}

Sir,

Pakistan is the $7^{\text {th }}$ populous country with a growth rate of $2.6 \%$, which if left unchecked, can reach upto 335 million by 2050 . Pakistan has a total fertility rate of $4.33 \%$ and a maternal mortality ratio of 297 per 100,000 live births, 1 making it one of the six countries contributing to more than $50 \%$ of all maternal deaths worldwide. ${ }^{2}$ Family planning provides the liberty of having the desired number of brith and adequate spacing among children, which is an effective way to reduce poverty, provide economic growth, lower fertility, and improve maternal and prenatal mortality rates. ${ }^{3}$

During this study (June- December 2017), conducted in district Mardan (Union Council Pat Baba), a total of 340 women of reproductive age group were included, out of which $322(94.7 \%)$ willingly participated. A questionnaire was developed and distributed in them. The total number of women of reproductive age was $322(100 \%)$, out of which $164(51 \%)$ were between 28-39 years, 102 (32\%) were between 15-27 years, and $56(17 \%)$ were between 40-49 years. The knowledge of contraceptive methods was known to $158(98 \%)$ in the Lady Health Workers (LHW) covered areas and was $145(90 \%)$ in the area where LHW services were not available. Moreover, $31(56 \%)$ of females in the LHW covered areas had knowledge about female sterilisation and this knowledge was $10(11 \%)$ in the uncovered area. The knowledge about male sterilization in the covered area was 91 $(19 \%)$ and was $18(6 \%)$ in the uncovered area. The knowledge about intrauterine contraceptive device (IUCD) was $98(70 \%)$ in the covered area and was 23 $(14 \%)$ in the uncovered area. The knowledge about injections was $156(97 \%)$ in the covered area and was $64(40 \%)$ in the uncovered area. The knowledge about implants was $55(34 \%)$ in the covered area and was 11 $(7 \%)$ in the uncovered area. The knowledge about male condoms was $140(87 \%)$ in the covered area and was $62(38 \%)$ in the uncovered area. The knowledge about female condoms was $4(2.5 \%)$ in the covered area and was $5(3 \%)$ in the uncovered area. The knowledge of emergency contraception method was $13(8 \%)$ in the covered area and $5(5 \%)$ in the uncovered area.

The most frequently used contraceptive method in the covered area was condom $17 \%$. Similar results were observed in a study conducted in KPK where condoms were the most common method of family planning. ${ }^{4} \mathrm{~A}$ KAP study done in Karachi also illustrated the highest use of condoms by the women of reproductive age. 5 A study conducted in tehsil Gujar Khan revealed that the women served by the LHWs were most frequently using condoms, followed by Tubal ligation, IUCD, injection/oral contraceptive pills and male sterilisation. ${ }^{6}$ However, a study conducted among females attending family planning centre in Hayatabad Medical Complex, Peshawar showed that injectable contraceptive use was the highest $(47 \%)$ followed by IUCD $(17 \%)$, pills $(16 \%)$, Tubal ligation (10.5\%), and condoms (9\%). ${ }^{7}$

There was a significant association between the LHWs presence and the knowledge scores. Moreover, there was a significant association between the LHWs presence and the preferred method used by the women. In those areas, condom was the most preferred method and in the uncovered areas it was withdrawal method. The principal reason for not using the modern methods of family planning was the fear of side effects, so counselling should be done regarding this problem.

\section{REFERENCES}

1. National Institute of Population Studies (NIPS) Islamabad Pakistan 2007. Status of women reproductive health and family planning survey: Main report. http://www.nips.org.pk/Date accessed 1/2/2015.

2. Hogan MC, Foreman KJ, Naghavi M, Ahn SY, Wang M, Makela SM, et al. Maternal mortality for 181 countries, 1980-2008: Systematic analysis of progress towards millennium development goal 5 . Lancet 2010; 375:1609-23.

3. Ministry of Health, Government of Pakistan. P-1 document of national programme for family planning and primary health care (FP and PHC). Islamabad, Pakistan. Ministry of Health, Government of Pakistan; 2003.

4. Jabeen R, Rauf $B$, Akhtar R, Siddique I. Factors affecting contraceptive practices of women in gynae \& obs unit of tertiary care hospital in KPK. KJMS 2014; 7:37-8.

5. Alagh V, Banerjee A. Acceptance of spacing method of contraception in Municipal Corporation of Dehli. Health Popul Perspect Issues 1995; 18:56-2.

6. Khan AW, Amjad CM, Hafiz A, Sharif R. Perceived individual and community barriers in the provision of family planning services by lady health workers in tehsil Gujar Khan. J Pak Med Assoc 2012; 62:1318-22.

7. Amin R. Choice of contraceptive method among females attending family planning center in Hayatabad Medical Complex, Peshawar. J Pak Med Assoc 2012; 62:1023-8.

Shahana Nisarl, Maria Khan ${ }^{2}$ and Uzma Nisar ${ }^{3}$

1 Department of Community Medicine, Bacha Khan Medical College, Mardan District, Khyber Pakhtunkhwa, Pakistan

2 Department of Pathology, Rehman Medical Institute, Peshawar, Pakistan

3 Department of Radiology, Armed Forces Institute of Radiology and Imaging, Military Hospital, Rawalpindi, Pakistan

Correspondence: Dr. Maria Khan, Department of Pathology, Rehman Medical Institute, Peshawar, Pakistan

E-mail:kmaria22@hotmail.com

Received: July 10, 2018; Accepted: November 27, 2018

.......... 